\title{
INVESTIGATING 'RELEVANCY' OF THE TRADITIONAL PRINCIPLE OF THE RIGHT OF APPROPRIATION OF OPEN SPACE AND FINA' IN CONTEMPORARY URBAN POOR COMMUNITIES IN CAIRO, EGYPT
}

\author{
Khaled GALAL AHMED \\ Architectural Engineering Department, College of Engineering, UAE University, Al Ain, 13393, \\ United Arab Emirates \\ E-mail:kgahmed1@yahoo.co.uk
}

Received 3 March 2014; accepted 26 October 2015

\begin{abstract}
Many scholars have questioned 'relevancy' of the principles of traditional urbanism where contradictory discourses have accumulated over time especially during the past few decades but unfortunately without a reliving answer. This research is a humble attempt to question this relevancy in our modern time in the domain of urban poor communities in Cairo through investigation one of the essential traditional housing principles, namely, "the right of appropriation of open spaces and fina". A method of qualitative/quantitative work has been embraced in which first, the investigated principle was defined from various sources of literature, then, field investigations through multiple case studies were conducted to address the question of relevancy to the urban poor communities today. It has been found that the principle is relevant to the residents' practices and significantly relevant to their attitudes. This opens the door for what might be considered as (re) legitimization of the principle, after considering its probable health and environmental impacts, through integrating it within the current social housing processes in Cairo and in Egypt as a whole.
\end{abstract}

Keywords: open space, fina', traditional urbanism, poor, urban, community, Cairo, Egypt.

\section{Introduction}

Seeking thoughts, ideas, and learning from traditional urbanism, rather than copying solutions from the West, has been an approach proposed by many Western, as well as Arab and Muslim, scholars and researchers (for example: Kazimee 2012; Antonio 1985; Ackerknecht, Kenworthy 1996; Mortada 2011; Asfour 1998; Steinberg 1991; Rapoport 1999). It is argued that instead of dealing with traditional architecture and urbanism in Arab-Islamic cities as products in a mere nostalgic manner, they should be dealt with as processes. This is because Arab-Islamic architecture and urbanism is more than simply a series of arches, domes, and decoration. It is a reflection of culture, religious beliefs, values, and social structure (Moughtin, Shalaby 1988; Asfour 1998; Ackerknecht, Kenworthy 1996; Ragette 2003; Davis, Neis 1996; Abu-Lughod 1987). Many scholars believe that learning from the traditional urban process might be viable today for plenty of reasons but the most important one is that the application of such principles managed to produce a built environment that achieved a considerable level of residents' satisfaction through social communication and interaction, respect for locality and local customs "urf", and social harmony and homogeneity. In contrast to the contemporary built environments, the built environment of the traditional Arab-Islamic city was intimately related to the social and cultural structure of the society which produced it (Akbar 1989; AlSayyad 1994; Steinberg 1991; Elaraby 1996).

On the other hand, some researchers have adopted a contradictory point of view. For example, Plimpton (1992) considers traditional values and culture irrelevant today due to the dominance of Western culture's manifestations and people's acceptance of them. Grabar (1985) wonders if the westernization process that took place in almost all walks of life in Cairo including urban development in the late nineteenth and early twentieth century broke a link with the traditional urbanism of the past or whether it could be considered as something new that would fit in the social history of Cairo. Arkoun (1990) believes that there is a need 
for continuous critical inquiry about the relevance, the usefulness and the righteousness of historical objective knowledge of the classical legacy of traditional culture.

Among the essential principles that had once shaped the traditional user-responsive built environment in Arab-Islamic cities was the users' right of appropriation of open spaces and fina' that was granted to the residents according to Islamic jurisprudence ( $f i n a$ ' means the space on the street abutting a property and is usually used exclusively by the owners of the property (Choueiri 2005)). Similar to other traditional principles this right was 'legally' obliterated as a result of the implementation of the Western-inspired municipal and building guidelines in Egypt by the early twentieth century. Accordingly, the current applied building and urban laws in Cairo consider residents' appropriations of their fina' and other open spaces "illegal actions".

\section{Research objective, questions and limitations}

Based on the above mentioned argument about relevancy/irrelevancy of the traditional principles that used to control the built environment, the research main objective is to examine to what extent is the influential traditional principle of the right of appropriation of open spaces and fina', though officially considered currently 'illegal' from the building regulations point of view, can be considered 'relevant' to the practices and attitudes of urban poor communities in Cairo today. If proved 'relevant' then this principle should be (re) legitimized and, thus, be integrated into the current urban and municipal legislations in Egypt but in a way that, of course, takes into consideration the complexity of contemporary urbanism. It is worth mentioning here that the meaning of 'relevancy' in this research is to see if even with the 'legal' absence of this juristic criterion, the contemporary practices of the urban poor people and their opinions are still indicating its viability and vividness.

Cairo, the capital city of Egypt, was selected as the main domain for the research investigations because, with its over 20 million inhabitants, it is the largest among all Egyptian cities in terms of population and area, and is therefore, severely affected by many housing-related problems especially affecting the urban poor. With the majority of the Egyptian people classified as poor people where about $42 \%$ of Egyptian population get less than 2 dollars a day (Dakhakhny 2013) and as one of the research limitations, the urban poor communities in Cairo were particularly selected for addressing the question of 'relevancy' of the investigated traditional principle, despite the fact that the principle had traditionally served all levels of wealth and social strata. Searching the relevancy of the principle in better-off communities is beyond the scope of this research.

The main two posed questions here are, first, 'how is this principle being practised in poor urban communities in Cairo today?' and, second, 'what are the residents' attitudes towards the legitimaization and (re)utilisation of this principle? and why have they adopted these attitudes?'. In order to undertake the research investigations to ultimately answer these two questions, the principle and its traditional application are briefly discussed in the following section.

\section{Users' right of appropriation of the Fina' in traditional urbanism of Cairo}

Traditionally, there were three spatial principles that commonly used in Arab-Islamic cities for regulating the built environment. They are haram, hima and fina? First, the haram is the buffer space surrounding a property (a well, building, forest or a river) and which is essential for its effective function such as streets and roads. People are prevented from violating the haram in order to maintain its integrity and to protect it against pollution and destruction. Meanwhile, hima is a reserved pasture, where trees and grazing lands are protected from indiscriminate harvest on a temporary or permanent basis and it is considered as a property dedicated to the well being of the whole community around it. Thirdly, the fina' is defined as the part of the street near the house, and does not extend more than half of the width of the street. In narrow lanes and dead-end streets, the fina' covers the whole area abutting the house, and usually extends to include the whole width of the lane (Barau 2010).

In a more precious definition fina' is defined as a space, about $1.0 \mathrm{~m}$. to $1.5 \mathrm{~m}$. wide, abutting exterior walls of a house, and primarily alongside streets and access paths. Fina' extends vertically alongside the walls of the house or the building (Hakim 2003). Akbar (1997) mentions that if every household 'revives' (i.e. builds on) the site it desires then properties will block each other's pathways and the built environment will be composed of compact properties abutting each other with no shared movement spaces. Thus, the fina' is the space added to the property without which the revived (built) land cannot function, as, for example, its road and pathway. The fina' is exclusively used by the residents as the inside of their dwellings (Fig. 1a, b, c).

The principle of the users' "right of appropriation of open spaces and fina"' was thoroughly recognized by Muslim jurists and scholars in the extant literature of the Near East, North Africa, and pre-1500 Spain. According to Islamic Jurisprudence (fiqh), as long as 


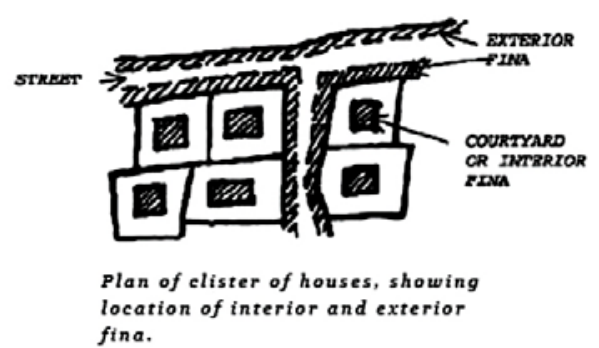

(a

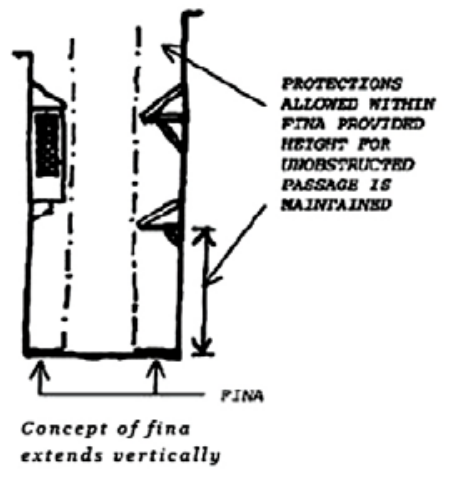

(b

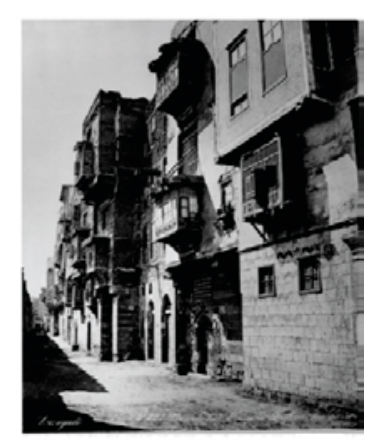

(c

Fig. 1a, b, c: The fina' (Source: a: Hakim, 2010 and b: University of Chicago Library.

Available on site: http://www.lib.uchicago.edu/e/su/mideast/photo/CairoStreet.html, first accessed on 8/12/2014).

this causes no harm, residents should be free to appropriate open spaces and fina' for a wide range of social and economic activities determined and permitted by the residents themselves without outside intervention (Akbar 1989; Hakim 2008). The principle had been an effective tool that allowed the articulation of the facades and thresholds along the public spaces.

Traditionally, users' appropriation of open space and fina' used to take different forms including builtin benches near entrances and troughs for vegetation. In wide streets and roads residents had the right to sell or buy goods on condition that doing so does not annoy anyone or harm the passers-by (Akbar 1997). Additionally, Akbar (1989) states that any individual could project part of his upper floor, such as mashrabias or cantilevers, on to a through street as long as no damage is caused to the public. Meanwhile, any passer-by had the right to object to such an action (Akbar 1997). Hakim (2008) adds that building even a room over a street joining two structures owned by the same person (known as sabat) was also allowed. According to the traditionally applied Islamic jurisprudence, the fina' may not be appropriated by others as it is considered to be a right belonging to the owners or tenants of the house. In the meantime, most Islamic schools of law approved short-term usage of the fina' by passers-by in activities such as sitting in its shaded area if it is not demarcated by the owner of the abutting property. This means that residents of a house had the right to prevent others from a steady use of their fina' (Akbar 1997).

In the fiqh the use of the fina' space precludes its being incorporated into its adjacent house or its being surrounded by a fence or a wall. Erecting simple structures such as benches or sheds, or planting a tree were traditionally permitted by most jurists as long as the neighbours do not complain. Akbar (1997) mentions that although the owner of a house possesses its fina', he was not allowed to sell it separately from the property. When there are closely adjacent properties, such as in the case of dead-end streets and small urban spaces, then afnia (plural noun of fina') were in this case jointly shared by owners and/or users of these properties and as such they had to respect the principle that usage of fina' by one of them should not cause harm to the neighbours (Hakim 2010). Maintenance of streets and private passageways, by keeping them clean and safe from obstructions, was also related to the responsibilities associated with using the fina' (Hakim 2003).

In case of disputes among residents concerning the application of the principle, the judgment was always on a case-to-case basis where no general rule was blindly applied to all cases. For example, in an instance a group of residents sued their neighbour who extended part of his house across their lane transforming it into two dead-end streets. The owner of this house claimed that when he bought the house the previous owner told him that the lane had originally been blocked by his house. Therefore, he was merely rebuilding his property on the street. He won his case. In contrast, in another similar case the judge ordered the demolition of a building that encroached upon and blocked a narrow through road. In both cases judgements were based on examining the previous history of the street where the main principle applied to through public streets was that: preceding action might continue while every new action was immediately questionable (Akbar 1997).

Given the Egyptian government abandonment of the traditional building principles including the principle of the users" "right of appropriation of the open space and fina' " and replacing them with mainly Western-inspired municipal and building regulation, the following sections are going to investigate the contemporary 'illegitimate' application of the principle by residents in poor urban communities in Cairo. These investigations are guided, of course, by the above mentioned research questions. 


\section{Field studies method}

Some of the urban poor of Cairo live in governmentbuilt public housing projects that were developed inside the city in the 1960s and in the newer urban settlements on its outskirts developed mainly in the 1980s and 1990s. Others live in numerous informal settlements that have been 'illegally' built on the city's urban fringes. This makes Cairo a fruitful domain for investigating the issue of 'relevancy' of this principle. The case study method was chosen because it allows the researcher to conduct a deep and intensive study of a manageably sized locality. This approach is perceived to be more suitable for in-depth study purposes of practices and socio-cultural attitudes, which is the main objective of the research as indicated by Fielding and Thomas (2008). Yin (2013) argues that a case study, as an empirical inquiry, is the preferred research strategy when "how", or "why," questions are being posed and when the focus of the research is on a contemporary phenomenon within some real-life context, which is exactly the case of this research. On the other hand, the multiple-case studies method was adopted, instead of a single case study, for a number of reasons. First is that the evidence from multiple cases is often considered more compelling, and the overall study is therefore regarded as being more robust (Yin 2013). Secondly, as the scope of the research is low-income housing in Cairo, three case studies were selected in order to represent the three main prevailing urban contexts of low-income housing in Cairo, namely, low-income public housing, transformed low-income public housing, and informal housing.

Three case studies were selected to represent the three main prevailing contexts of urban poor housing in Cairo. The $6^{\text {th }}$ neighbourhood of the $6^{\text {th }}$ district in the $6^{\text {th }}$ of October city in the Greater Cairo Region, The Masaken Mohie scheme and the Manial Sheha settlement (Fig. 2). Respectively they represent a public housing scheme $(\mathrm{PH})$, a transformed public housing scheme (TPH) (i.e. the public housing project in which the residents extended most of the housing units after acquiring ownership from the government) and an informal housing settlement (IH).

The criteria, which guided the selection of these case studies, were: first, they represent the common and shared characteristics of the three prevailing low-income housing contexts in Cairo with their various amount of control that residents have over the decision-making processes. Secondly, they accommodate socially established and stable communities. Thirdly, they reflect various phases of on-going changes and adaptation processes in the built environment. Finally, they are accessible to the researcher. Data gathered from the case studies covered practices, experiences, perceptions and attitudes about the current utilization of the investigated principle. These case studies provided an important opportunity to make comparisons between the three distinctive urban poor housing contexts in each of which users are practising different amount of control over the decisionmaking processes pertaining to their housing environment. The case studies were extensively carried out using a mixture of qualitative and quantitative data collection techniques in order to maximise the amount of data collected and also to enable methodological triangulation. The sources of qualitative data collected were first; direct observation of the residents' practices concerning the application of the principle. Photographs, sketches and notes were used as recording tools for these observations. Second, the residents' responses to the open ended questions from face-to-face structured interviews in order to obtain data about their justification for their attitudes and preferences. On the other hand, quantitative data were obtained from the closed questions in a structured interview-aided questionnaires and the description of the built environment through recorded observations as well as some documentary sources.

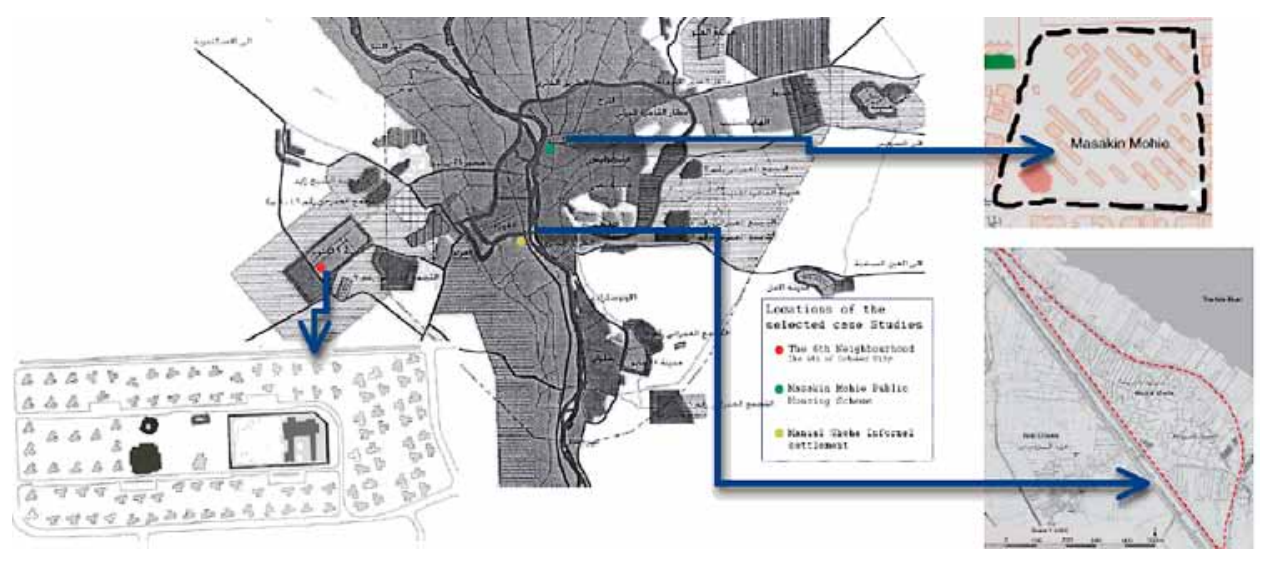

Fig. 2. The locations of the selected case studies in the Greater Cairo Region (prepared by the author according to a map obtained from Ministry of Housing, Utilities and Urban Communities, 2011: 107) 
A total of one hundred and twenty households were selected as the research sample, where the householder or a member of the household was personally interviewed by the researcher. The relatively limited sample size was mainly influenced by the research objectives as it allowed depth and richness of details of data collected but yet it was sufficient to be as representative as possible of the area studied. The non-availability of satisfactory sampling frames for the population in the case study areas under investigation made the possibility of using a pure, random sampling method difficult. Therefore, cluster or multi-stage sampling was adopted in which clusters were firstly determined for each case study in a way that secured geographically well-distributed clusters across the selected case study areas and, more importantly, reflected the different urban characteristics within each case study. Then, a number was assigned to each household within each cluster in the three case studies. Using a simple random sampling method, sub-samples were determined within the identified clusters. Despite the unrestricted random sampling procedures the findings of the research remain illustrative of a qualitative understanding of residents' practices and attitudes. Table 1 summarizes the characteristics of the interviewees in the three case studies.

For investigating the practices of the residents' concerning the appropriation of open space and fina' the asked question was: "What sort of activities do you, or your neighbours, conduct in the open spaces ( $f$ ina') abutting your dwelling?". And, for investigating the residents' attitudes towards the right of appropriation of the fina' the asked question was: "Local authorities should control residents' appropriation of open spaces and fina'. What is your opinion about this statement? And why do you

Table 1. Characteristics of the interviewees in the three case studies

\begin{tabular}{|c|c|c|c|c|c|}
\hline & Characteristics of the Interviewees & $\begin{array}{l}\text { The } 6^{\text {th }} \text { of } \\
\text { October PH }\end{array}$ & $\begin{array}{c}\text { Masakin Mohie } \\
\text { TPH }\end{array}$ & $\begin{array}{c}\text { Manial Sheha } \\
\text { IH }\end{array}$ & $\begin{array}{l}\text { All Case } \\
\text { Studies }\end{array}$ \\
\hline \multicolumn{6}{|c|}{ Person interviewed } \\
\hline 1 & The householder & $80 \%(32)$ & $60 \%(24)$ & $82.5 \%(33)$ & $74.2 \%(89)$ \\
\hline 2 & Other member of the household & $20 \%(8)$ & $40 \%(16)$ & $17.5 \%(7)$ & $25.8 \%(31)$ \\
\hline \multicolumn{6}{|c|}{ Gender } \\
\hline 1 & Male & $77.5 \%(31)$ & $77.5 \%(31)$ & $100 \%(40)$ & $85 \%(102)$ \\
\hline 2 & Female & $22.5 \%(9)$ & $22.5 \%(9)$ & $0 \%(0)$ & $15 \%(18)$ \\
\hline \multicolumn{6}{|c|}{ Age } \\
\hline 1 & Under 20 & $2.5 \%(1)$ & $00.0 \%(0)$ & $00.0 \%(0)$ & $00.8 \%(1)$ \\
\hline 2 & $20-35$ & $45 \%(18)$ & $42.5 \%(17)$ & $25 \%(10)$ & $37.5 \%(45)$ \\
\hline 3 & $36-50$ & $42.5 \%(17)$ & $30 \%(12)$ & $45 \%(18)$ & $39.2 \%(47)$ \\
\hline 4 & $51-65$ & $10 \%(4)$ & $17.5 \%(7)$ & $27.5 \%(11)$ & $18.3 \%(22)$ \\
\hline 5 & Over 65 & $00.0 \%(0)$ & $10 \%(4)$ & $2.5 \%(1)$ & $4.2 \%(5)$ \\
\hline \multicolumn{6}{|c|}{ Marital status } \\
\hline 1 & Married & $80 \%(32)$ & $57.5 \%(23)$ & $87.5 \%(35)$ & $75 \%(90)$ \\
\hline 2 & Divorced & $00.0 \%(0)$ & $2.5 \%(1)$ & $2.5 \%(1)$ & $1.7 \%(2)$ \\
\hline 3 & Widowed & $2.5 \%(1)$ & $15 \%(6)$ & $00.0 \%(0)$ & $5.8 \%(7)$ \\
\hline 4 & Single & $17.5 \%(7)$ & $25 \%(10)$ & $10 \%(4)$ & $17.5 \%(21)$ \\
\hline \multicolumn{6}{|c|}{ Occupational status } \\
\hline 1 & In a full-time job & $75 \%(30)$ & $55 \%(22)$ & $80 \%(32)$ & $70 \%(84)$ \\
\hline 2 & In a part time or a casual job & $5 \%(2)$ & $10 \%(4)$ & $2.5 \%(1)$ & $5.8 \%(7)$ \\
\hline 3 & Jobless or pensioner & $20 \%(8)$ & $35 \%(14)$ & $17.5 \%(7)$ & $24.2 \%(29)$ \\
\hline \multicolumn{6}{|c|}{ Educational qualification } \\
\hline 1 & Bachelor degree or above & $22.5 \%(9)$ & $17.5 \%(7)$ & $25 \%(10)$ & $21.7 \%(26)$ \\
\hline 2 & Secondary school & $25 \%(10)$ & $37.5 \%(15)$ & $32.5 \%(13)$ & $31.7 \%(38)$ \\
\hline 3 & Preparatory school & $22.5 \%(9)$ & $12.5 \%(5)$ & $00.0 \%(0)$ & $11.7 \%(14)$ \\
\hline 4 & Primary school & $12.5 \%(5)$ & $10 \%(4)$ & $15 \%(6)$ & $12.5 \%(15)$ \\
\hline 5 & Without educational qualification & $17.5 \%(7)$ & $22.5 \%(9)$ & $27.5 \%(11)$ & $22.5 \%(27)$ \\
\hline
\end{tabular}


think so?". For the processing and analysis of the research qualitative data obtained from the residents' responses to these questions, the answers were written in transcripts and were then analyzed manually using the grounded theory method (Smith et al. 2001) where the researcher aimed at producing common (or contradictory) themes and patterns from the data, which can be used as a basis for interpretation. Here the researcher followed the recommendation of Fielding and Thomas (2008) that the first step in qualitative data analysis is to develop the set of categories into which the data could be coded. What emerged from the analysis of residents' structured interviews (what questions) were themes and patterns that were quantified as numbers that thus permitted the use of statistical treatment. The phrases representing the emergent themes from the open-ended questions (why questions) were refined and then coded. These phrases were then counted and their frequencies were analyzed using SPSS software. Some quotations from respondents' answers were used to enrich the results.

On the other hand, data gathered from direct observation were associated with the previously mentioned data in the analysis process to maximize and enrich the results and was used as a means of data triangulation.

\section{Residents' utilisation of, and attitudes towards, the appropriation of open spaces and fina'}

Residents' activities in open spaces and fina'

There are many activities that residents undertake, even 'illegitimately' from the municipal regulations point of view, in open spaces and afnia in the front of their houses or residential blocks. The sort of prevailing activities differs for each of the three case studies. The Manial Sheha IH came first in terms of the intensity of activities residents undertake in these open spaces. In this case study, residents undertake a wide spectrum of social and economic activities in these spaces with almost no constraints imposed on them by the local authority. Field observations and the face-to-face interviews with the respondents in Manial Sheha IH revealed that there are three particular prevailed activities in the open spaces and afnia. First come both selling and buying of goods $(92.5 \%)$ and children playing (92.5\%). In the Manial Sheha IH most of the shop owners use the fina' in the front of their shops as a temporary extension for their shops where they usually display goods for sale or they use the fina' as a sitting area for food shop customers (Fig. 3a, b). Children in the Manial Sheha IH usually appropriate open spaces as playgrounds where they gather together and play (Fig. 4a, b, c).

The activity ranked second in dominance is social interaction through talking and sitting in the fina' in the front of houses (90\%). Residents, either male or female, used to sit and talk on mastabas (built-in benches) in the fina' (Fig. 5a, b, c). One of the respondents in Manial Sheha IH said that, "I and my cousins usually gather in the evenings and sit on the mastaba to chat about many issues. This preserves good relations among us." Appropriating open spaces and fina' as working

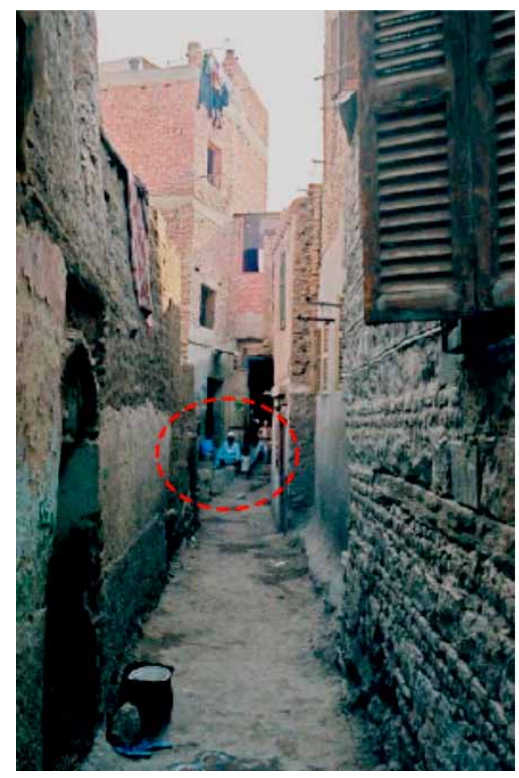

a)

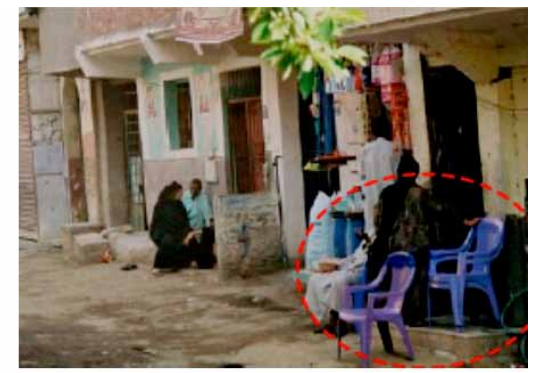

b)

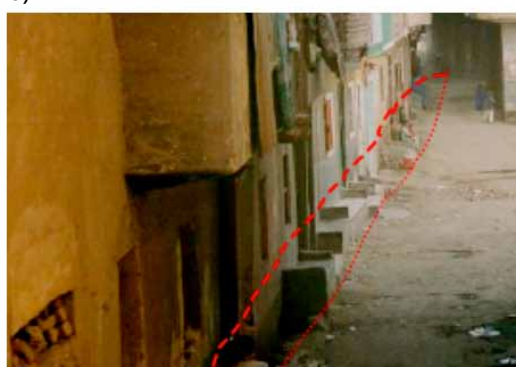

c)

Fig. 3 a, b, c: Sitting and talking is one of the prevailing social activities for residents in Manial Sheha, that both men and women undertake in open spaces and fina's. A few examples; in photograph (a) residents in one of the culs-de-sac sitting in the front of their house. In photographs (b) and (c) residents are sitting on mastabas in the front of their houses, or as in (b) on plastic chairs in the front of shops 


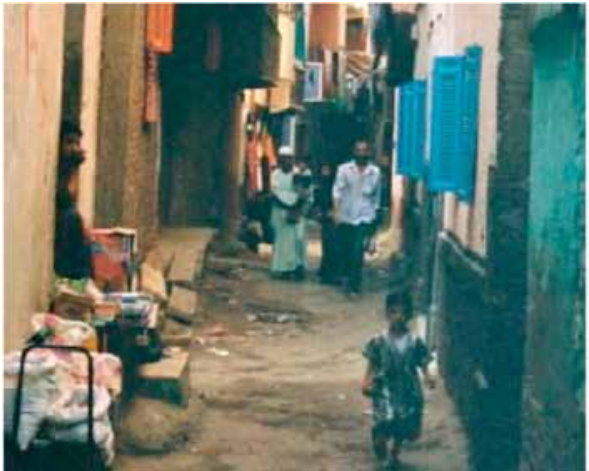

a)

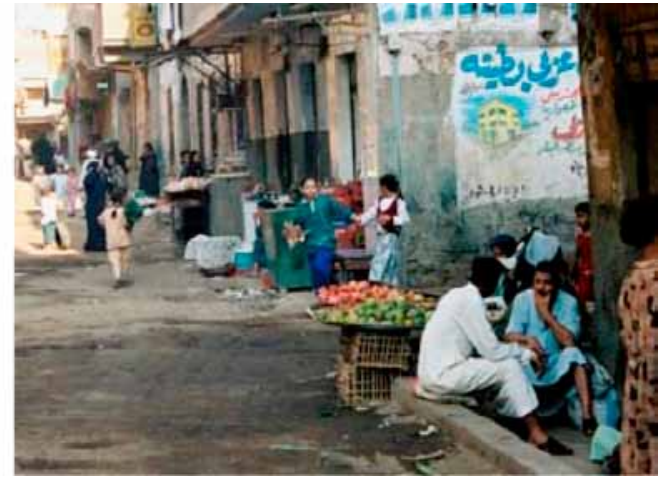

b)

Fig. 4 a, b: Appropriation of urban spaces and fina's in selling different goods where, as in photographs (a) and (b), shops owners lay out some goods in the front of their shops or, as in photograph (c) some vendors appropriate these places temporarily during the day

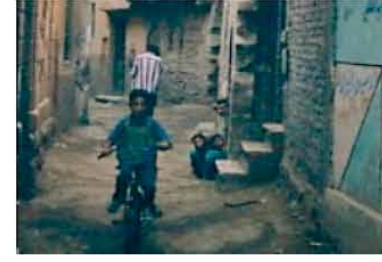

(a

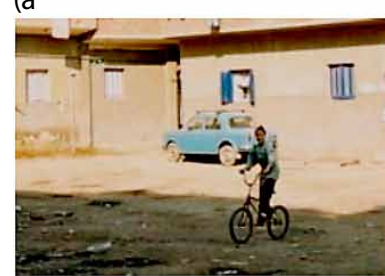

(b

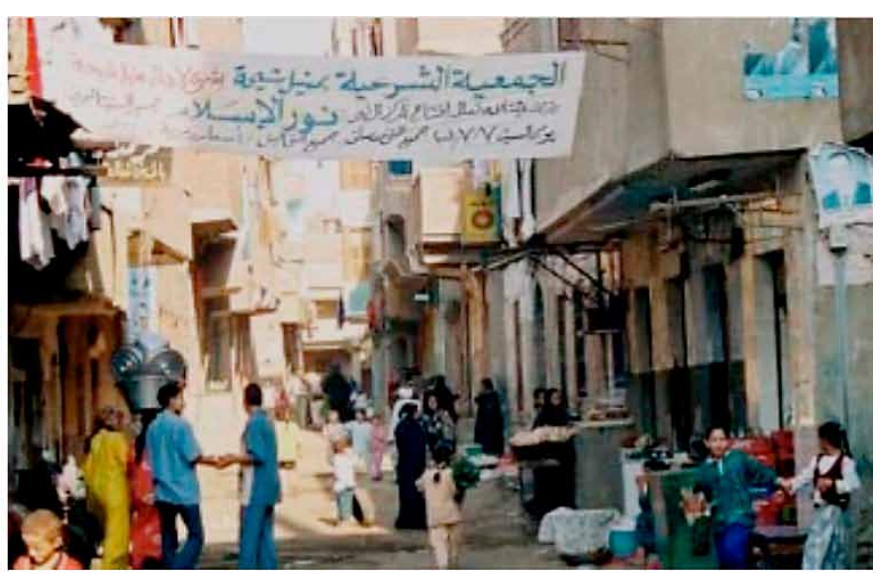

c)

Fig. 5 a, b, c: Children in the Manial Sheha appropriate open spaces as playgrounds

places was a less observed activity in Manial Sheha $\mathrm{IH}$ (50\%). Meanwhile, gardening (30\%) and rearing poultry or animals in these spaces were the least practiced activities (27.5\%).

Through observation, it seemed that a convention or local custom (urf) had developed among many residents in the Manial Sheha IH to have wedding celebrations in temporary wood-and-fabric (ferashah) structures in the open spaces. In spite of the high level of noise produced from these activities it is rare that residents complain. In brief, residents in the Manial Sheha IH appropriate the open spaces and fina' in their region for a wide spectrum of social and economic activities. No local authority's imposed regulative constraints seem to hinder any of these 'illegitimate' activities which residents are apparently completely free to undertake.

In the Masakin Mohie TPH, residents are also seem free to undertake different social and economic activities in the open spaces and afnia. Nonetheless, these activities are relatively less intensive than those found in the Manial Sheha IH. The most dominant activities undertaken by residents in the Masakin Mohie TPH in the spaces between blocks are children playing (80\%) and gardening (77.5\%). Gardens are either a small pocket garden in the fina' in the front of a residential block, or a larger one in the public open space in between residential blocks (Fig. 6a, b). In the meantime, appropriation of open spaces and fina' in other activities such as rearing poultry (12.5\%), sitting and talking (15\%), selling things (15\%) and work (17.5\%) were less practiced. Appropriation of common public spaces in Masakin Mohie TPH was not exclusive to the open spaces where many social activities were observed, but also took place in the common corridors and staircases within the residential blocks themselves. 
The appropriation of open spaces and fina' in the $6^{\text {th }}$ of October PH was obviously less intensive than the other two case studies. This might be attributed to the much less amount of control residents enjoy over the decision-making process in this case study. As both observed and mentioned by the respondents, the most practised activities are sitting and talking (37.5\%), gardening (32.5\%) and children playing (25\%) (Fig. 7a, b).

In terms of the temporary appropriation of the fina in social interaction, it was noticed that the residents (especially women) who live in the same block usually gather together in the evening to sit and chat in the gardens in open spaces and afnia in the front of their residential blocks. They usually bring refreshments and food with them while their children use these spaces as playgrounds. Less dominant activities include selling goods $(15 \%)$ and rearing poultry (15\%). Work activities by residents were the least practiced in this case study (5\%). As in the case of the Masakin Mohie TPH, some of the residents in the $6^{\text {th }}$ of October PH have appropriated the common spaces inside their residential blocks such as corridors and lobbies for various, but limited, activities.

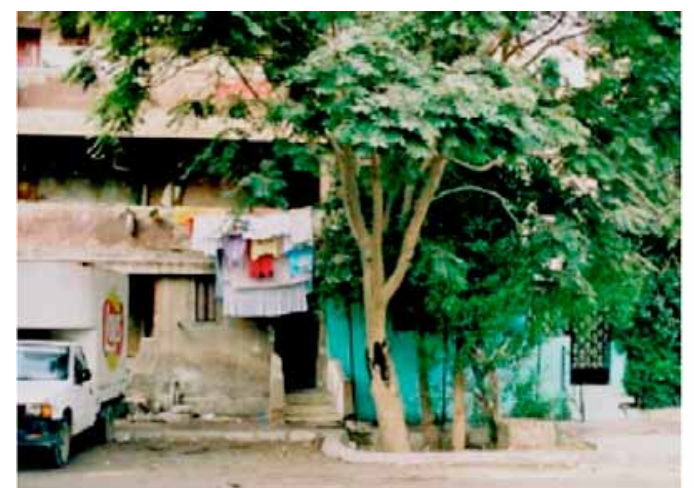

a)

Fig. 6a, b: Some examples of appropriating the fina's for gardening as a significant prevalent activity by residents in Masakin Mohie transformed public housing case study

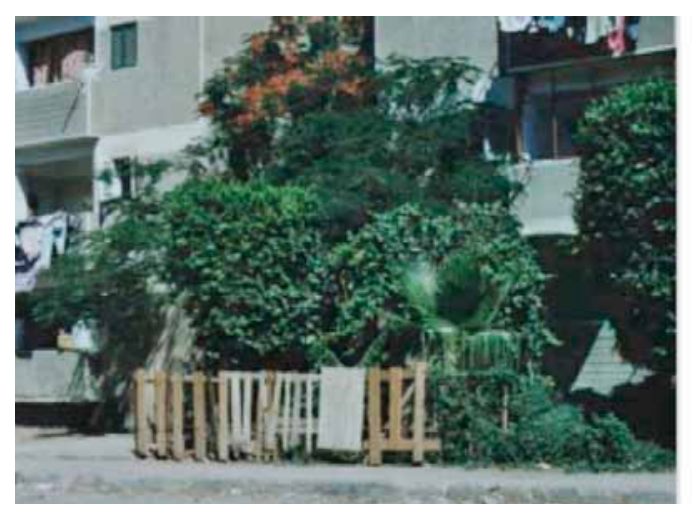

a)
Residents' attitudes towards whether local authorities should control appropriation of open spaces and fina'

The majority of the respondents $(60 \%)$ in the three case studies collectively, either disagreed or strongly disagreed with the notion that the local authority should control residents' permanent or temporary appropriation of open spaces and fina'. The majority of the respondents in both the $6^{\text {th }}$ of October PH (67.5\%) the Manial Sheha IH (65\%) adopted the same attitude while almost half of the respondents in the Masakin Mohie TPH (47.5\%) adopted this attitude as well (Fig. 8).

As illustrated in Table 3, the major significant justification for the respondents who adopted this attitude in the three case studies collectively, was that the appropriation of open spaces in these socio-economic activities is essential for the residents well being (29.2\%) [25\% in the $6^{\text {th }}$ of October PH, 27.5\% in Masakin Mohie $\mathrm{TPH}$ and 35\% in Manial Sheha IH]. The second justification for this attitude in the three case studies was that the socio-economic activities involved in appropriating open spaces and fina' usually causes no real harm to

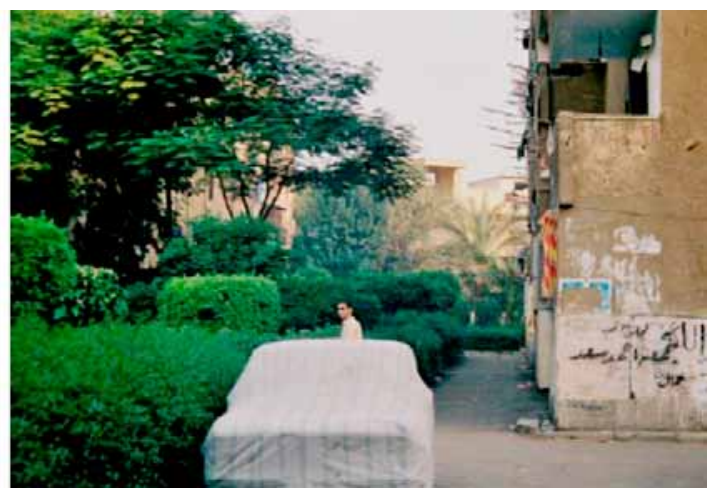

b)

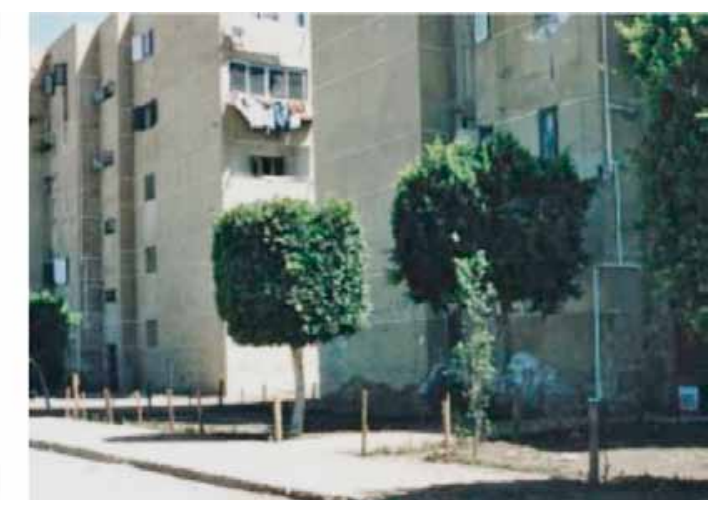

b)

Fig. 7a, b: Some examples of the residents' appropriation of the fina's for gardening as a significant activity in the 6 th of October $\mathrm{PH}$ 


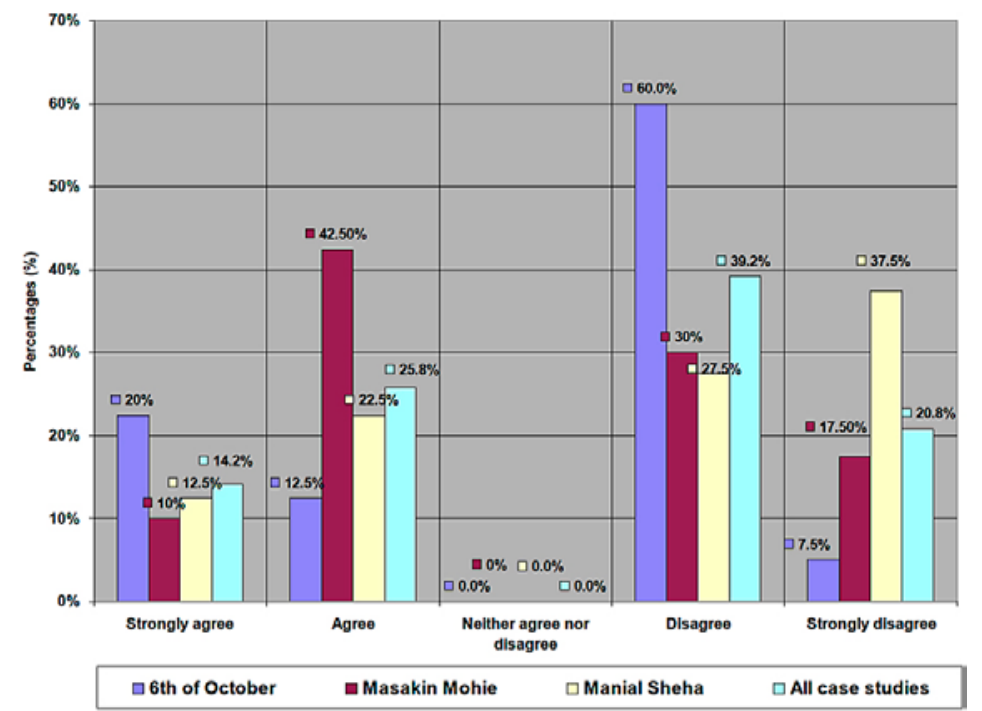

Fig. 8. The government should control the temporary residents' appropriation of open spaces and fina's the community $(10.8 \%)\left[12.5 \%\right.$ in the $6^{\text {th }}$ of October $\mathrm{PH}, 7.5 \%$ in Masakin Mohie TPH and $12.5 \%$ in Manial Sheha IH]. The third justification was that there are no real alternatives available for accommodating these essential activities (10\%) $\left[20 \%\right.$ in the $6^{\text {th }}$ of October $\mathrm{PH}$, None in Masakin Mohie TPH and 10\% in Manial Sheha $\mathrm{IH}]$. The fourth, in significance, justification in the three case studies was that residents can themselves control the ways that these open spaces and fina' are appropriated and are able to prevent any likely harm that might affect the community $(7.5 \%)\left[7.5 \%\right.$ in the $6^{\text {th }}$ of October PH, 12.5\% in Masakin Mohie TPH and 2.5\% in Manial Sheha IH]. For example, one resident in the $6^{\text {th }}$ of October PH mentioned that; "we have no problem with those travelling sellers who are temporarily appropriating the fina' in the front of our blocks as long as they clean the place after they finish and we have already told them that they have to do so." Another resident in the Manial Sheha IH claimed that; "it is difficult for the city council to control people's actions in the fina' and open spaces. It is only people's behaviour that can adjust their activities in a way that does not cause harm to the others. This is what the Prophet (Mohammed) said."

The least significant justification for this attitude in the three case studies was that it is appropriate for these socio-economic activities to be undertaken in open spaces and fina' $(2.5 \%)$ [2.5\% in the $6^{\text {th }}$ of October PH, None in Masakin Mohie TPH and 5\% in Manial Sheha IH]. A resident in the $6^{\text {th }}$ of October $\mathrm{PH}$ stated that; "Travelling sellers are nearer to us than the central market which is relatively far away especially in this hot weather."

On the other hand, a considerable minority of the respondents (40\%) in three case studies collectively adopted the opposite attitude where they either agreed or strongly agreed that the local authority should control the temporary appropriation of open spaces and fina' $\left[32.5 \%\right.$ in the $6^{\text {th }}$ of October PH, $52.5 \%$ in Masakin Mohie TPH and 35\% in Manial Sheha IH] (Fig. 8). Two almost equally significant reasons justified this attitude. First, is that local authority's control usually helps maintain a healthier residential environment (14.2\%) [7.5\% in the $6^{\text {th }}$ of October PH, $22.5 \%$ in Masakin Mohie TPH and $12.5 \%$ in Manial Sheha IH]. Secondly, is that residents' activities should be conducted in particular places allocated specifically for them but not in the streets or public spaces (13.3\%) [17.5\% in the $6^{\text {th }}$ of October PH, 15\% in Masakin Mohie TPH and $7.5 \%$ in Manial Sheha $\mathrm{IH}$ ]. For example, One of residents in the $6^{\text {th }}$ of October $\mathrm{PH}$ who objected the appropriation of the fina' for commercial activities mentioned that; "it would be better if the ground floor of each residential block would be allocated for shops."

Other less significant reasons for this opposing attitude were that local authority's control over these activities will preserve a 'civilised' and ordered visual character of the residential areas $(6.5 \%)\left[7.5 \%\right.$ in the $6^{\text {th }}$ of October PH, 7.5\% in Masakin Mohie TPH and 6.7\% in Manial Sheha $\mathrm{IH}$ ] and that local authority intervention is needed in order to control harmful activities initiated by some residents in the open spaces and afnia (5\%) [None in the $6^{\text {th }}$ of October PH, 7.5\% in Masakin Mohie TPH and 7.5\% in Manial Sheha IH]. The least significant reason was that local authority's control of such activities would enhance the traffic flow in the streets of the residential areas $(0.8 \%)$ [None in the $6^{\text {th }}$ of October PH, None in Masakin Mohie TPH and 2.5\% in Manial Sheha IH].

Finally, in light of the earlier analysis, Table 2 summarizes the degree of 'relevancy' of the right of appropriating open spaces and fina', to the respondents' practices, preferences and attitudes in each of the three case studies individually and in the three of them collectively. 


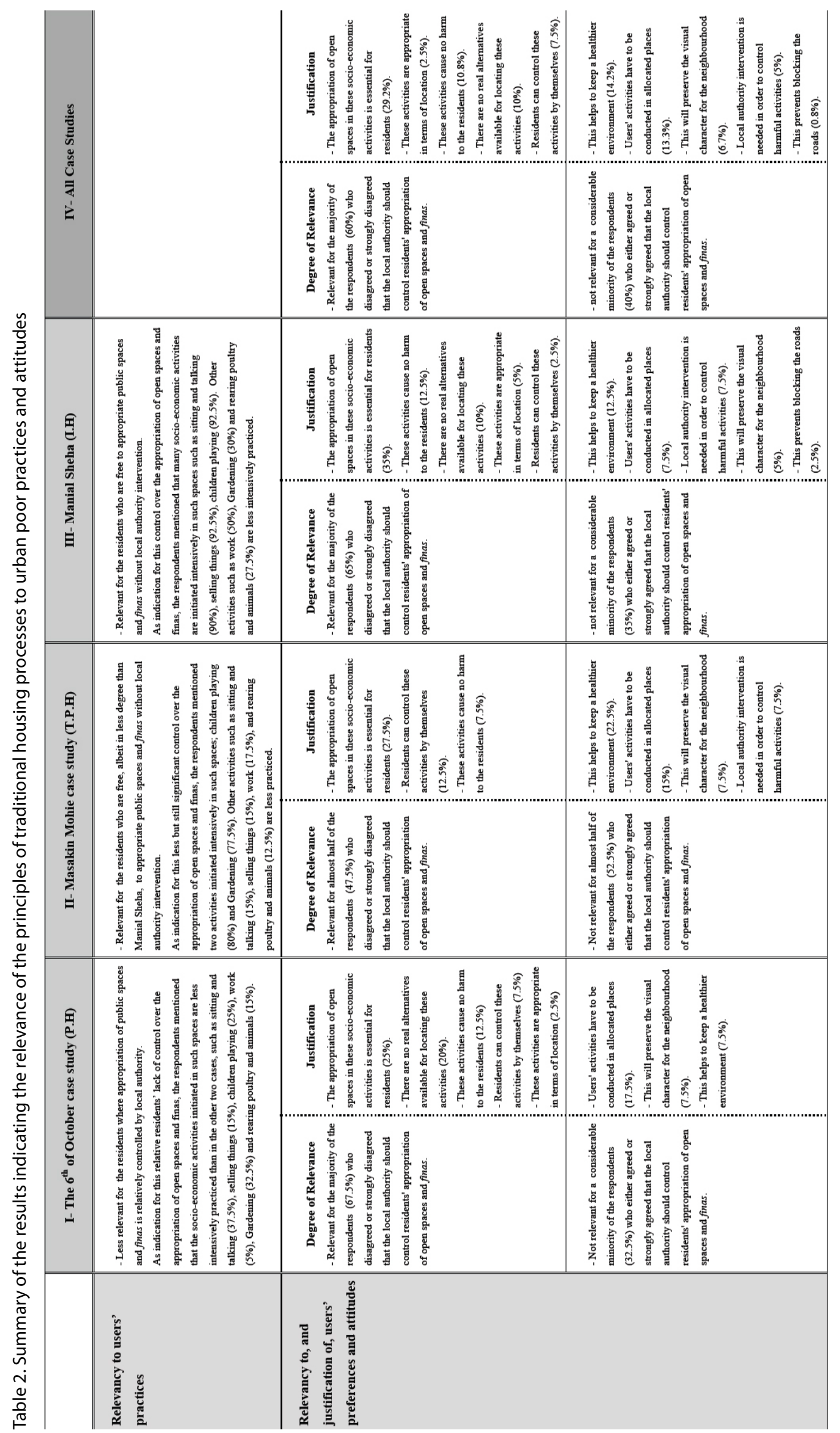




\section{Discussion}

In the literature review two main arguments have been identified in terms of the relevancy of traditional housing principles today. The first argument is that traditional principles might be a viable source for learning lessons for the present where individuals might be guided by a set of shared building norms/ rules derived from their own culture, as has happened in traditional Arab-Islamic cities. The advocates of this argument believe that these shared building rules could be reutilised creatively because, for them, history and traditions provide a fertile base from which to learn and, when necessary, from which to recycle experiences especially in housing processes. Accordingly, it is not too late to learn a valuable lesson from traditional urban processes and to convert the current system to a performance-based mechanism of control, as it has been traditionally. On the other hand, the contradictory argument states that tradition values and culture are absolutely irrelevant today due to the dominance of Western cultural manifestations, which have been embraced and accepted by professionals and ordinary people alike. Therefore, it is believed that Western models in everything from clothes and cooking to buildings and art have become the operative norm for Arab and Muslim communities all over the world. Other researchers believe that the relevancy of traditional principles is a researchable question that needs to be investigated. The results of this research lies within this third category where the relevancy of the traditional ruling principle of the users' right of appropriation of open space and fina' was investigated.

The findings of this research, and as an answer for the first question of it, indicate that the 'right of appropriation of open spaces and fina" in the urban housing environments in urban poor communities, as a main principle of traditional building processes, is still, to a large extent, relevant to the residents' actions in all three contexts of the urban poor communities in Cairo, but with some variation in the degree of relevance between these contexts attributed mainly to the amount of control residents already have over the decision-making processes. Residents in the Manial Sheha $\mathrm{IH}$ are appropriating the open spaces and afnia in a wide spectrum of social and economic activities. It appears that no local authority's imposed regulative constraints seem to hinder any of these activities which residents are almost completely free to undertake. Manial Sheha IH came first in terms of the intensity of activities residents undertake in these open spaces. In the Masakin Mohie TPH, with its different housing context, residents seem generally free to appropriate, either collectively or individually, the public in-between spaces or afnia in the front of the residential blocks. Nonetheless, the amount of socio-cultural activities, as indicated by the respondents, seems less here than those initiated in the open spaces and afnia in the Manial Sheha IH. The least, but still significant, amount of the users' socio-economic appropriation of open spaces was noticed in the $6^{\text {th }}$ of October $\mathrm{PH}$ where residents do not yet have full control over the decision making processes, or at least they still have a feeling of lack of control as they are still paying off to the local authority for their housing units. Full ownership of their housing units after some years might encourage them to appropriate the open spaces and afnia in a more active and intensive way as has happened in the case of the Masakin Mohie TPH.

Relevance of this principle to the residents' practices should be interpreted here as a reflection of urf or the shared community convention, rather than, of course, as a 'legitimate' controlling principle recognised and applied by the local authority as was the case traditionally. The failure of the local authorities to rigorously apply the current building regulations, especially in the public housing and transformed public housing case studies, has encouraged, to some extent, the residents to spontaneously apply this principle despite being considered as 'illegitimate' because it violates the currently implemented, or rather supposed to be implemented, building regulations in Cairo. As the research findings revealed, this is by no means to claim here that the current residents' practices are based solely on traditional 'religious' values but it seems also motivated by contemporary influential economic and social conditions as has been noticed in the types of activities that residents practices in the three contexts.

As an answer for the second research question about the residents' attitudes towards the re(utilization) of the principle legitimately as it used to be applied traditionally, i.e without intervention from local authorities, this was found to be relevant to the majority of the respondents especially in the $6^{\text {th }}$ of October $\mathrm{PH}$ and Manial Sheha IH case studies. The main reasons for this preference were that, first, the appropriation of open spaces and fina' for various socio-economic activities is essential for residents. This is well understood in light of the economic stratum of these urban poor communities. Second, is that such socio-economic activities do not cause harm to the community. Third, is that there are no real alternatives available for accommodating these essential activities. Fourth, is that residents can themselves efficiently control the way spaces are appropriated to prevent any probable harm that might affect the community. Nonetheless, a considerable minority 
of the respondents in the three case studies, regardless of the amount of control which users have over the housing processes, believe that local authority's control over the appropriation of open spaces and fina' is essential mainly for the sake of preserving environmental and health considerations and also because they believe that the residents' activities should be conducted in particular places allocated specifically for them but not in the streets or public spaces.

\section{Conclusions}

Based on the research results, the users' right of appropriation of open spaces and fina', which have been found to be relevant to the residents' practices and significantly relevant to their attitudes, is recommended to be (re)recognized officially as one of the guiding principles for the decisions affecting the mixed use and the modification of adaptable urban housing spaces. Thus, the main lesson that architects, planners and urban decision makers could learn from the outcomes of this research is that they should 'legitimately' allow, through housing planning/design schemes and relevant housing development legislations, urban poor communities in Cairo and other Egyptian cities more freedom to participate in the decision making process pertaining to the appropriation of open spaces and afnia for whatever purposes they see fit, but under some conditions that aims at achieving protections for the passers-by, the environment and community health. The claim here is not arguing in favor of turning whatever a certain community of urban poor people does or convenes to accept, into the sole source of legislation in urbanism, which is of course at odds with the basic tenets of Islamic law (Shari'a), which upholds a rule that people's urf is recognized in legislation only as long as it does not contradict with any explicit scriptural ruling in Islamic law such as the no harm principle. In addition, 'legitimization' of the principle, if happened, should be based on a case-to-case evaluation rather than on one-fits-all rule.

Finally, given the potential benefits of the 'legitimization' of this principle in both social and economic domains on the urban poor community levels, integrating this principle within the local contemporary social housing development programs in Cairo and in Egypt as a whole, needs to be carefully studied taking into account the constraints associated with health considerations and environmental hazards, ease of access, pedestrian movement and transportation which all can be fields for further research.

\section{References}

Abu-Lughod, J. L. 1987. The Islamic city: historic myth, Islamic essence, and contemporary relevance, International Journal for Middle East Studies 19: 155-176. http://dx.doi. org/10.1017/S0020743800031822

Acherknecht, D.; Kenworthy, G. 1996. Tradition and adaptation, Journal of The International Association For The Study of Traditional Environments 8(1): 47-48.

Akbar, J. 1997. Crisis in the built environment: the case of the Muslim city. Singapore: Concept Media.

Antonio, J. 1985. The exploding metropolis, Arts \& The Islamic World 2(4): 29-46.

Akbar, J. 1989. Losing interest: blight of the Muslim city, Open House International 14(3): 28-35.

Al-Sayyad, N. 1994. Balance and imbalance: the Islamic Middle Eastern city between tradition and modernity, Alam Albena 159: 6-8.

Arkoun, M. 1990. Islamic cultures, developing societies, modern thought, in R. Powell (Ed.). Expressions of Islam in Buildings. Singapore: Concept Media, 49-64.

Asfour, Kh. 1998. Cultural crisis, Architectural Review 203(1213): 52-60.

Barau, A. S. 2010. Integrating Islamic models of sustainability in urban spatial planning and management, in S. Lehmann, H. Al Waer, J. Al Qawasmi (Eds.). Sustainable architecture and urban development. Amman: Centre for the Study of Architecture in the Arab Region.

Choueiri, Y. M. (Ed.) 2005. A companion to the history of the Middle East. Oxford: Blackwell Publishing Ltd.

Dakhakhny, F. 2013. Egyptian food bank: 42\% of Egyptians live under poverty line. Almasryalyoum Newspaper, [online], [cited 14 February 2014]. Available from Internet: http:// www.almasryalyoum.com/News/details/170200

Davis, H.; Neis, H. 1996. Contemporary initiatives and traditional process, Journal of The International Association For The Study of Traditional Environments 8(1): 70.

Elaraby, K. 1996. Neo-Islamic architecture and urban design in the Middle East: from threshold to adaptive design, Built Environment 22(2): 138-150.

Grabar, O. 1985. The meaning of history in Cairo, in A. Evin (Ed.) The expanding metropolis: coping with the urban growth of Cairo, in Proceedings of Seminar Nine in the Series Architectural Transformations in the Islamic World, 11-15 November 1984, Cairo, Egypt. Singapore: Concept Media [for] Aga Khan Awards, 1-24.

Hakim, B. S. 2008. Arabic-Islamic cities: building and planning principles. London: RKP.

Hakim, B. S. 2010. Generative processes for revitalising historic towns or heritage districts, International Network for Traditional Building, Architecture \& Urbanism 1(19).

Hakim, B. 2003. Learning from traditional Mediterranean codes. Gaithersburg: the Town Paper.

Kazimee, B. A. (Ed.) 2012. Heritage and sustainability in the Islamic built environment. London: WIT Press.

Fielding, N.; Thomas, H. 2008. Qualitative interviewing, in N. Gilbert (Ed.) Researching social life. California: Sage Publications, Inc., 123-143.

Ministry of Housing, Utilities and Urban Communities. 2011. Mubarak and urbanization: present achievements and future 
expectations. Cairo: Ministry of Housing, Utilities and Urban Communities (in Arabic).

Mortada, H. 2011. Traditional Islamic principles of built environment. Oxford: Routledge.

Moughtin, J. C.; Shalaby, M. T. 1988. Activity systems as determinates to housing design in Muslim cities, part 2, Alam Albena 47: 4-5.

Plimpton, Ch. 1992. Cultural reidentification expressed through vernacular architecture, Traditional Dwellings and Settlement Review 4(1): 21.

Ragette, F. 2003. Traditional domestic architecture of the Arab region. Wurttemberg: Axel Menges

Rapoport, A. 1999. A framework for studying vernacular architecture, Journal of Architectural and Planning Research 16(1): 52-63.

Smith, M. E.; Thorpe, R.; Lowe, A. 2001. Management research. London: Sage Publications.

Steinberg, F. 1991. Architecture and townscape in today's Cairo: the relevance of tradition, Built Environment 58(346/347): 75-86.

Yin, R. K. 2013. Case study research design and methods. London: Sage Publications, Inc.

\section{KHALED GALAL AHMED}

Architectural Engineering Department, College of Engineering, UAE University, Al Ain, 13393, United Arab Emirates.

E-mail:kgahmed1@yahoo.co.uk

Dr., Associate Professor at United Arab Emirates University, Architectural Engineering Department. He got his $\mathrm{PhD}$ in 2003 from the University of Wales Cardiff, in the UK. He is interested in the research issues related to sustainability in both its architectural and urban dimensions with special focus on socio-cultural sustainability and sustainable community development. He participated with research papers in many regional and international conferences and workshops. He also published the results of his research work in various indexed international/regional journals. 